\title{
Spiritual needs of dying and emergency health care
}

\author{
I. Andrasi \\ Catholic University in Ruzomberok, Slovakia; St. Elizabeth University, Bratislava, Slovakia
}

\begin{abstract}
Dying process can take different forms, and each death is related to leave-taking of a human with what he liked, with those whom he loved and who were close to him. Daily contact with the dying is very difficult, very demanding not only in physical terms, but especially in terms of psychological burden. The essence of care for dying patients is to ensure adequate quality of life that is highly affected by understanding of human existence and the meaning of human life. Paramedics must realize that quality of life is associated with satisfying the needs that in each patient is different, so the quality of life is a very individual concept. Coping with dying is significantly affected by the ability of their very faith in God's existence, length of service and communication skills.
\end{abstract}

Key words: spiritual needs, dying, paramedics, emergency health care.

\section{Introduction}

Dying process can take different forms, and each death is related to leave-taking of a human with what he liked, with those whom he loved and who were close to him. The World Health Organization (WHO) defines health as a state of complete physical, mental and social wellbeing and not merely the absence of disease or malfunction. In the modern era health is increasingly complement from the perspective of the needs and the spiritual well-being of the patient, which in many cases dominates in dying patients. Health care workers in daily contact with the dying are not just health professionals, for whom the care of these patients is very demanding in terms not only physical, but especially in terms of psychological burden. Paramedics involve salvaging not only sick part of the human body, but they work with sick/dying person and subsequently with relatives/survivors. They act by their professional interventions, as well as all their personality, relationship with them, degree of professional qualities, level of competence and professional adaptation [1]. The essence of care for dying patients is to ensure adequate quality of life that is highly affected by understanding of human existence and the meaning of human life. A paramedic must realize that quality of life is associated with satisfying the needs that in each patient is different, so the quality of life is very individual concept. Through interview with the patient a paramedic has the opportunity to find out their spiritual needs and then set a goal of satisfying these needs. Satisfying spiritual needs helps to cope with suffering more tolerable. Satisfying spiritual needs is of great importance for the sick person. A paramedic should particularly respect the faith of the sick, to obtain information on their spiritual needs, to inform the patient and relatives [2]. The concept of spiritual literacy is introduced as the nurse's and paramedic's ability to read the spiritual signs of the human experience. 
Main concern is to assist the patient to alleviation. The participants resolved this by discerning the healing path, which comprises three stages: tuning in on spirituality, uncovering deep concerns, and facilitating the healing process. these three stages are accompanied all the way by the participants' willingness to overcome own comfort zone and building a trusting relationship [3].

Our aim was to find out the attitude of emergency workers to religion and spirituality as well as the impact of traumatic events at work on their attitude to spirituality of patients; to find out how paramedics perceive spiritual needs of patients and how often they meet the requirements of the prayer, the presence of a priest.

\section{Survey methods}

In our survey, we used the online standardized questionnaire - The Spiritual Needs Assessment for Patient (SNAP) concerning psychosocial and spiritual needs. The sample consisted of 88 respondents: $69.4 \%$ males and $30.4 \%$ females. Age of the respondents was $35.4 \pm 9.7$ years. Length of practice: 5 years $42.9 \%, 5-15$ years $37.6 \%$, more than 15 years $19.5 \%$. Religion and the existence of God: $74 \%$ believe in the existence of God. We analyzed questionnaire by ANOVA statistics with $p<0.01$. Survey was held in 2014 and 2015. Reliability of a psychometric test - Cronbach's alpha $=0.921$.

\section{Results}

The results were analyzed in relation between the perception of spiritual needs in dying patient and the length of practice. We found that perception of spiritual needs of the patient depends on the length of service and spiritual needs of emergency workers. There is a significant difference between all three groups (according to length of practice) as is shown in Table 1.

Table 1. Perception of spiritual needs in dying patients.

\begin{tabular}{|c|c|c|c|c|c|}
\hline \multicolumn{6}{|c|}{ ANOVA } \\
\hline & Sum of Squares & df & $\begin{array}{c}\text { Mean } \\
\text { Square }\end{array}$ & F & Sig. \\
\hline Lenght of practice $<\mathbf{5}$ years & \multicolumn{1}{|c|}{} \\
\hline Between Groups & 7.753 & 2 & 3.385 & 6.344 & $\mathbf{. 0 0 0}$ \\
\hline Lenght of practice $\mathbf{5}-\mathbf{1 5}$ years \\
\hline Between Groups & 9.703 & 2 & 4.847 & 4.804 & $\mathbf{. 0 0 3}$ \\
\hline Lenght of practice $>\mathbf{1 5}$ years & 4.992 & 2 & 2.477 & 2.585 & $\mathbf{. 0 0 8}$ \\
\hline Between Groups &
\end{tabular}

The spiritual needs of a dying person can sometimes be overlooked in the busyness of physical care. However for those experiencing it, spiritual distress is very real. The time, when the patient faces their own death is the time to start thinking about ways of meeting the spiritual needs [4]. $94.73 \%$ of respondents with up to 5 years' experience states that they are focused primarily on the medical aspects; $63.6 \%$ of emergency workers with 5-15 years' experience stated that they perceive the needs of patients and meet them as much as possible; $82.35 \%$ with experience longer than 15 years stated that suspension of transport would request the presence of a priest prior to transport to the hospital and act without any delays. The results are shown in Fig. 1. 


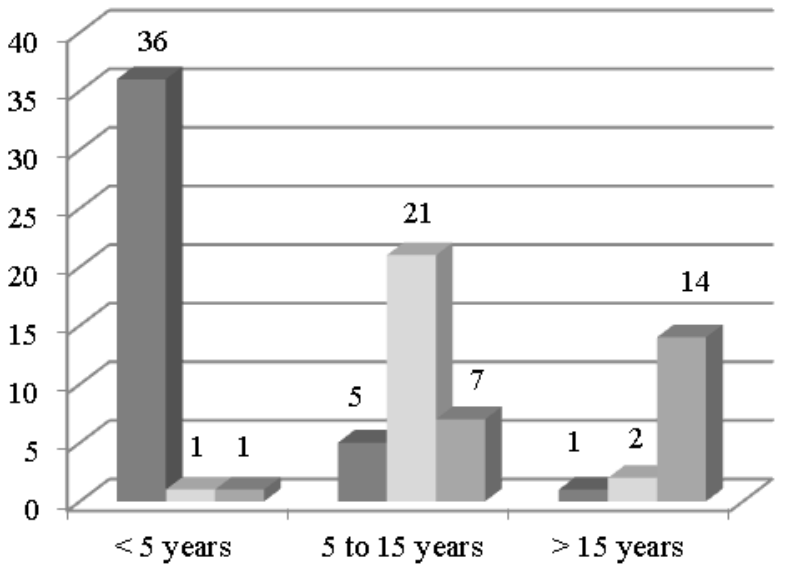

\author{
- Focus on medical \\ aspects - no delay \\ of transport \\ Focus on both \\ medical aspects \\ and demand of the \\ patient
Focus on demand of patients - \\ primarily
}

Fig. 1. Focus influenced by length of practice.

How often paramedics meet the requirements of the prayer, the presence of the priest and how to implement it? Most often it is the ratio between cities and countryside 17\%:83\%. The problem is the lack of preparedness for the situation. Similar research was held also in different care organizations in a rural community in Sweden with participation of $n=33$ paramedics. The results showed that less than $50 \%$ lacked education in the spiritual/existential areas [5].

Often we meet medical staff's fear of dying. Often they ask themselves how it will affect them personally and how it affects their career attitudes. At the beginning of work in their profession, or while preparing for a career, medical staff is expected to experience a greater fear than after several years of practice. A study conducted in Hungary, however, shows other results. Cross-sectional comparative study conducted to evaluate and compare the current and future ambulance personnel's fear of death and its influencing factors including 106 participants (active rescue ambulance personnel, $n=45$ persons; paramedic students, $n=61$ ) discovered that there is no significant difference between the levels of fear of death of the present and future ambulance personnel [6].

An important fact is the perception of the quality of dying. This factor is associated with the staff's perception of high-quality dying and death. Positive death experiences are associated with absence of patient pain, dyspnoea, anxiety, or agitation and the presence of spiritual, psychological, and culturally appropriate care for the patient and family [7]. This topic is becoming more and more relevant, as the incidence of patients requiring this type of symptom care is on the increase. The results of research held in Slovakia in oncology patients had shown that the symptom occurrence of patients in palliative care directly correlates with the quality of their lives. Among the most common symptoms reported were: loss of appetite $(n=102=99 \%)$, weight loss $(n=101=98 \%)$ and pain $(n=97=$ 94.2\%). The symptoms that were least reported were: dizziness $(n=31=30.1 \%)$, flatulency $(n=27=26.2 \%)$ and itching (pruritus) $(n=16=15.5 \%)[8]$.

\section{Conclusion}

Paramedics are interested and want to talk about the spiritual life of the patient and satisfy their spiritual needs. It is important that professionals be properly prepared when patients need this communication. An evidence-based training intervention could provide such 
preparation [9]. But it is significantly affected by their faith in God's existence, length of service and communication skills. In severe traumatic events and raised doubts about the strength of faith and ability of God to do miracles it does not affect their spiritual life and faith. Paramedics with active spiritual life are happier in their profession, they easier overcome traumatic events, are more active in approach to meeting the spiritual needs of the patient and are more balanced in medical assistance.

\section{References}

1. E. Moraučíková, Multidisciplinary care about remainder, Log. Pol. 2, 82-87 (2015)

2. K. Zrubáková, A. Herinková, Význam spirituality u onkologicky chorých. Posudzovanie symptómov a spirituálnych potrieb pacientov $v$ paliatívnej starostlivosti. SAP 94-114 (2015)

3. S. Hlinková, E. Moraučíková, Spirituality and Spiritual Needs in the Palliative Care. Satisfying spiritual needs of dying. Tribun, 31-52 (2014)

4. T. Giske, P.H. Cone, Discerning the healing path - how nurses assist patient spirituality in diverse health care settings. J. of Clin. Nurs. 24, 2926-2935 (2015)

5. G. Eriksson, T.W. Bergstedt, Ch. Melin-Johansson, The need for palliative care education, support, and reflection among rural nurses and other staff: A quantitative study. Pal.\& Sup. Carre 13, 265-274 (2015)

6. E. Pek, Z. Szekely-Benke, B. Radnay et al. Am, balance personnel and paramedic student's attitudes regarding death and dying. Crit. Care Med. 43, 342 (2015)

7. R. Bennett, J. Proudfoot, What does the staff think? Factors associated with clinical staff perceptions of what constitutes high-quality dying and death. J. of Hosp.\& Pal. Nurs. 18, 470-476 (2016)

8. V. Littva, M. Šichman, Troublesome Symptoms in Palliative Care. 7th International Conference of Hospice and Palliative Care. Solen, 6-13 (2015)

9. I. Henoch, S. Strang, M. Browall et al. Development of an existential support training program for health care professionals. Pal. \& Sup. Carre 13, 1701-1709 (2015) 